\title{
Recipient Age and Mortality Risk after Liver Transplantation: A Population-Based Cohort Study
}

\author{
Hsiu-Pin Chen ${ }^{1,2}$, Yung-Fong Tsai ${ }^{1,2}$, Jr-Rung Lin ${ }^{3}$, Fu-Chao Liu ${ }^{1,2}$, Huang-Ping Yu ${ }^{1,2 *}$ \\ 1 Department of Anesthesiology, Chang Gung Memorial Hospital, Taoyuan, 333, Taiwan, 2 College of \\ Medicine, Chang Gung University, Taoyuan, 333, Taiwan, 3 Clinical Informatics and Medical Statistics \\ Research Center and Graduate Institute of Clinical Medicine, Chang Gung University, Taoyuan, 333, Taiwan \\ *yuhp2001@adm.cgmh.org.tw
}

\section{Abstract}

The aim of the present large population-based cohort study is to explore the risk factors of age-related mortality in liver transplant recipients in Taiwan. Basic information and data on medical comorbidities for 2938 patients who received liver transplants between July 1 , 1998, and December 31, 2012, were extracted from the National Health Insurance Research Database on the basis of ICD-9-codes. Mortality risks were analyzed after adjusting for preoperative comorbidities and compared among age cohorts. All patients were followed up until the study endpoint or death. This study finally included 2588 adults and 350 children [2068 (70.4\%) male and $870(29.6 \%)$ female patients]. The median age at transplantation was 52 (interquartile range, 43-58) years. Recipients were categorized into the following age cohorts: $<20(n=350,11.9 \%), 20-39(n=254,8.6 \%), 40-59(n=1860$, $63.3 \%)$, and $\geq 60$ ( $n=474,16.1 \%$ ) years. In the total population, 428 deaths occurred after liver transplantation, and the median follow-up period was 2.85 years (interquartile range, 1.2-5.5 years). Dialysis patients showed the highest risk of mortality irrespective of age. Further, the risk of death increased with an increase in the age at transplantation. Older liver transplant recipients ( $\geq 60$ years), especially dialysis patients, have a higher mortality rate, possibly because they have more medical comorbidities. Our findings should make clinicians aware of the need for better risk stratification among elderly liver transplantation candidates.

\section{Introduction}

Liver transplantation (LT) has become the routine treatment for patients with liver failure or end-stage liver disease. Because of advances in surgical techniques, anesthesia, infection control, critical care and immunosuppressants [1], the survival rate of LT recipients has greatly improved, and the number of LT patients has consequently increased, to include candidates previously considered too old or having too many medical comorbidities to receive LTs [2]. 
In particular, the number of older LT recipients has increased more rapidly than that of younger recipients, as an increasing number of healthy people are entering old age. Further, individuals aged $<30$ years may have a substantially lower risk of contracting hepatitis B virus (HBV) infection, which causes chronic hepatitis and consequently liver cirrhosis [3], may be substantially lower in aged $<30$ years because the Taiwanese government has enforced HBV vaccination since 1984 [4]. The association between age-related comorbidities and postoperative mortality risk remains a concern for LT recipients, especially the elderly ones $[5,6]$, and careful evaluation is essential for elderly LT recipients, who potentially have more comorbidities. Preoperative assessment and long-term care has unique challenges in this particular transplant group [7]. Despite this, the recent contemporary literature lacks large population-based trials, and risk quantification and stratification among elderly LT recipients have not been analyzed yet.

In order to improve clinical practices, we analyzed all deaths after LT in Taiwan in the past 14.5 years with a focus on age-related risk factors of mortality. The present study aimed to assess the risk factors of pre-LT for mortality rate.

\section{Materials and Methods Data Collection}

This was a retrospective national population-based cohort study by Taiwan's National Health Insurance (NHI). The NHI program in Taiwan has gradually enrolled nearly $99.9 \%$ of the Taiwanese population (23.28 million). The Bureau of National Health Insurance (BNHI) has collected claim data in a de-identified and computerized format and established the National Health Insurance Research Database (NHIRD). This database provides registration files and original claim data from out- and inpatient care for reimbursement, including dates and orders of clinical visits and diagnostic codes from International Classification of Disease, Revision 9, Clinical Modification (ICD-9-CM). According to the NHI program, patients who need LT need to be diagnosed by transplant surgeons or gastroenterologists.

This study was evaluated and approved by the NHIRD research committee (NHIRD-103103) and the institutional review board of Chang Gung Medical Foundation (103-0102B).

\section{Patient Definition and Selection}

We identified LT patients from the catastrophic illness database between July 1998 and December 2012 using the ICD-9-CM codes V427 (LT status) and 996.82 (complications of transplanted liver). During this period, 4086 post-LT patients were registered in the NHIRD. LT recipients who did not undergo transplantation within this time period were not included in the present study; thus, 1148 patients who lacked a code for LT surgery $(505,75020 \mathrm{~A}$, or 75020B) were excluded, resulting in a final cohort of 2938 recipients.

Medical comorbidities were defined as five recorded outpatient department (OPD) diagnoses or one recorded inpatient department (IPD) diagnosis during the preoperative period. All diagnoses were verified using the configured ICD-9-CM codes. Further, the following comorbidities were defined using these codes: diabetes mellitus (ICD-9-CM 250), hypertension (ICD-9-CM 401-405), acute myocardial infarction (ICD-9-CM 410), congestive heart failure (ICD-9-CM 428), stroke (ICD-9-CM 430-438), peripheral vascular disease (ICD-9-CM 443), chronic pulmonary disease (ICD-9-CM 490-496), peptic ulcer (ICD-9-CM 533), chronic hepatitis (ICD-9-CM 571.4), liver cirrhosis (ICD-9-CM 571.5), psychosis (ICD-9-CM 295-299), cancer (ICD-9-CM 140-239), hepatic cellular carcinoma (ICD-9-CM 155), renal failure (ICD9-CM 584-586) and infection (ICD-9-CM 038). Death was defined as the termination of national health insurance or receipt of insurance death codes. 


\section{Measurements}

The primary outcome was long-term mortality in the LT recipients. The survival time of the LT recipients was calculated as the date of surgery to the date of death. Variables used to estimate the risk of mortality included demographic and clinical characteristics, such as age, gender, and comorbidities.

\section{Statistical Analysis}

The chi-square test or Fisher's exact test was used to examine differences in demographic characteristics among different age cohorts. Risk ratios were used to compare the transplant cohort with the general population. Kaplan-Meier estimates with log-rank tests were used to compare survival during follow-up among the age cohorts. In the mortality analyses, patients were followed up until an event (death) or censoring (loss to follow-up or end of the follow-up period), whichever occurred first. All statistical tests were two-sided, and a $p$-value $<.05$ was considered statistically significant. Cox proportional hazards regression modeling was used to analyze the effect of age-related mortality, when modeled as a continuous and as a categorical variable, to predict the age as a risk factor after risk adjustment. Analyses were performed using SAS statistical software (version 9.3; SAS Institute Inc.; Cary, NC, USA).

\section{Results}

\section{Study Population and Baseline Characteristics}

A total of 2938 LT procedures in 2588 adults and 350 children were performed and recorded in the Taiwanese NHIRD during the study period. The overall median age at the time of transplantation was 52 years (interquartile range: $43-58$ years), and the study included 2068 (70.4\%) male and $870(29.6 \%)$ female patients. Recipients were categorized into the following age cohorts: $<20$ years $(\mathrm{n}=350,11.9 \%), 20-39$ years $(\mathrm{n}=254,8.6 \%), 40-59$ years $(\mathrm{n}=1860$, $63.3 \%)$, and $\geq 60$ years $(\mathrm{n}=474,16.1 \%)$.

Older patients were more likely to have hypertension, diabetes mellitus, coronary arterial disease, chronic pulmonary disease, heart failure, stroke, and liver cirrhosis than young patients. Moreover, chronic hepatitis was the most common medical comorbidity and was recorded in 2702 (91.97\%) patients. Table 1 shows the significant differences between the basic characteristics among the age groups.

\section{Data Accuracy}

In order to verify the quality of the data in the NHIRD, we extracted the number of patients receiving LTs from the Taiwan Transplant Database. From 2005 to 2012, 2775 LTs were registered in the Taiwan Transplant Database, and during the same period, the number in the NHIRD was 2723, indicating a small discrepancy between these databases (concordance: $98.1 \%)$.

\section{Mortality Risk}

Fig 1 shows a comparison of mortality rates between the transplant population and the general Taiwanese population during the same time period according to age group. The rates were significantly higher in the transplant population than in the general population.

Figs 2 and 3 present the unadjusted Kaplan-Meier survival curves for first-year patient survival and the risk of death after LT during the 14.5-year study period, respectively, according to recipient age. The six-month and first-year patient survival rates were similar between the $<20$ years, $20-40$ years, $40-60$ years, and $\geq 60$ years groups, showing only a slightly significant 
Table 1. General demographics of liver allograft recipients.

\begin{tabular}{|c|c|c|c|c|c|c|c|}
\hline Variable & Age groups & $<20$ & $20-40$ & $40-60$ & $\geq 60$ & Total & $p$-value \\
\hline Number (\%) & & 350 & 254 & 1860 & 474 & 2938 & \\
\hline \multirow[t]{2}{*}{ Gender } & Male & $173(49.43)$ & $191(75.20)$ & $1432(76.99)$ & $272(57.38)$ & 2068 (70.39) & $<.0001$ \\
\hline & Female & $177(50.57)$ & $63(24.80)$ & $428(23.01)$ & $202(42.62)$ & $870(29.61)$ & \\
\hline \multirow[t]{16}{*}{ Medical comorbidity } & HTN & $1(0.29)$ & $12(4.72)$ & $398(21.40)$ & $187(39.45)$ & $598(20.35)$ & $<.0001$ \\
\hline & Pulmonary disease & $34(9.71)$ & 17 (6.69) & $263(14.14)$ & $106(22.36)$ & $420(14.30)$ & $<.0001$ \\
\hline & $\mathrm{DM}$ & $1(0.29)$ & $15(5.91)$ & $458(24.62)$ & $140(29.54)$ & $614(20.90)$ & $<.0001$ \\
\hline & Stroke & $2(0.57)$ & $4(1.57)$ & $53(2.85)$ & $32(6.75)$ & $91(3.10)$ & $<.0001$ \\
\hline & CAD & $3(0.86)$ & $2(0.79)$ & $114(6.13)$ & $83(17.51)$ & $202(6.88)$ & $<.0001$ \\
\hline & $\mathrm{CHF}$ & $1(0.29)$ & $2(0.79)$ & $29(1.56)$ & $17(3.59)$ & $49(1.67)$ & 0.0018 \\
\hline & CKD / ESRD & $1(0.29)$ & $7(2.76)$ & $76(4.09)$ & $25(5.27)$ & $109(3.71)$ & $<.0001$ \\
\hline & Dialysis & $1(0.29)$ & $2(0.79)$ & $24(1.29)$ & $4(0.84)$ & $31(1.06)$ & 0.3411 \\
\hline & Liver cirrhosis & $155(44.29)$ & 175 (68.90) & 1613 (86.72) & $415(87.55)$ & $2358(80.26)$ & $<.0001$ \\
\hline & Chronic hepatitis & $221(63.14)$ & $218(85.83)$ & 1781 (95.75) & 458 (96.62) & $2678(91.15)$ & $<.0001$ \\
\hline & Alcoholic hepatitis & $0(0.00)$ & $63(24.80)$ & 425 (22.85) & $58(12.24)$ & $546(18.58)$ & $<.0001$ \\
\hline & HBV & $4(1.14)$ & 108 (42.52) & $962(51.72)$ & 189 (39.87) & 1263 (42.99) & $<.0001$ \\
\hline & $\mathrm{HCV}$ & $0(0.00)$ & $0(0.00)$ & $19(1.02)$ & $6(1.27)$ & $25(0.85)$ & 0.0597 \\
\hline & Peptic ulcer & $8(2.29)$ & $84(33.07)$ & $1069(57.47)$ & $271(57.17)$ & $1432(48.74)$ & $<.0001$ \\
\hline & Psychosis & $0(0.00)$ & $20(7.87)$ & $267(14.35)$ & $98(20.68)$ & $385(13.10)$ & $<.0001$ \\
\hline & Esophageal varices & $70(20.00)$ & $89(35.04)$ & 712 (38.28) & 148 (31.22) & 1019 (34.68) & $<.0001$ \\
\hline \multirow[t]{2}{*}{ Cancer } & $\mathrm{HCC}$ & $8(2.29)$ & $61(24.02)$ & $812(43.66)$ & $255(53.80)$ & $1136(38.67)$ & $<.0001$ \\
\hline & Non-HCC & $13(3.71)$ & $15(5.91)$ & $164(8.82)$ & $52(10.97)$ & $244(8.30)$ & 0.0008 \\
\hline
\end{tabular}

Chi-square test or Fisher's exact test were used to examine the differences in the demographic characteristics of liver transplant patients between the age cohorts. HTN = hypertension, $\mathrm{DM}=$ diabetes mellitus, $\mathrm{CAD}=$ coronary artery disease, $\mathrm{CHF}=$ congestive heart failure, CKD / ESRD = chronic kidney disease/end stage renal disease, $\mathrm{HBV}=$ chronic $\mathrm{B}$ hepatitis infection, $\mathrm{HCV}=$ chronic $\mathrm{C}$ hepatitis infection, $\mathrm{HCC}=$ hepatocellular carcinoma.

doi:10.1371/journal.pone.0152324.t001

difference $(\log$-rank $p=.0314$ and $p=.0372)$; however, the five-year and during the study period patient survival rates in these groups were significantly different (Log-rank $p<.001$ and $p<.0001)$. These findings indicated that survival was strongly related to age at the time of transplant, with older patient groups showing higher mortality.

This study identified 342 deaths that occurred posttransplantation during a median followup period of 2.85 years (interquartile range: $1.2-5.5$ years). Fig 4 shows the changes in mortality at the cut-off age of 60 years, which was selected arbitrarily. The risk of death was $17.92 \%$ among liver transplant recipients aged $\geq 60$ years during a median follow-up of 2.85 years

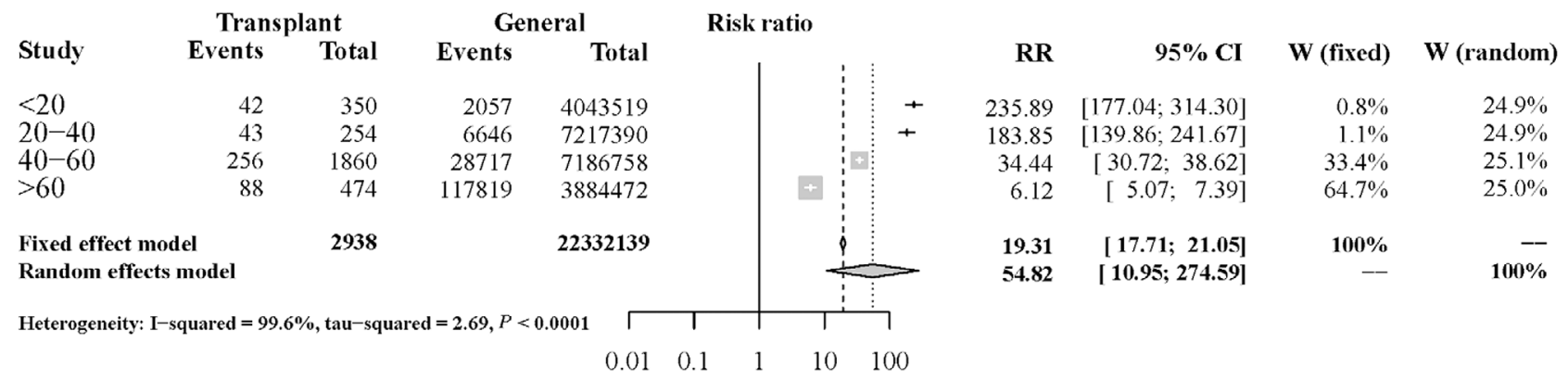

Fig 1. Mortality risk ratios of liver transplant recipients versus the general population. 


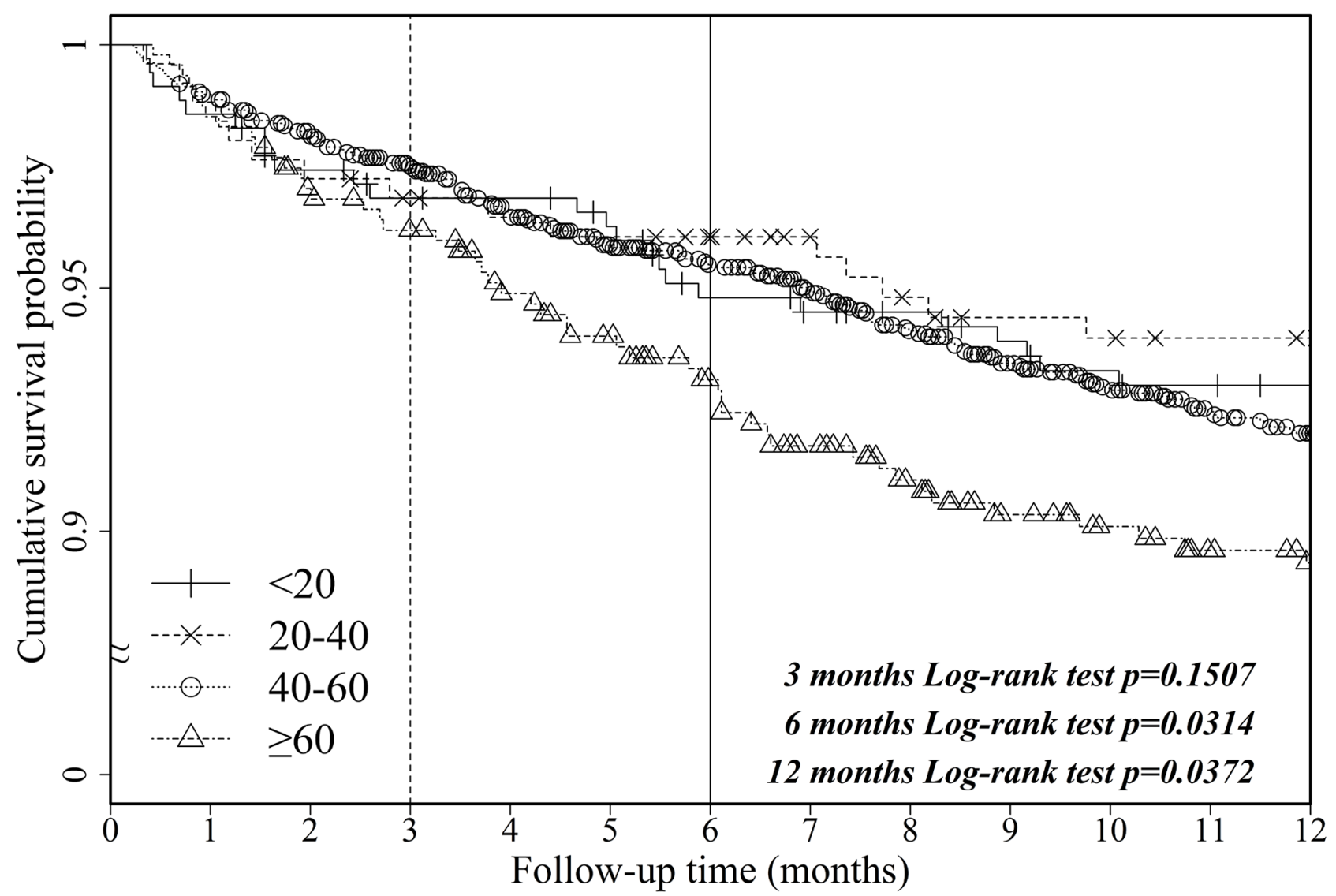

Fig 2. Unadjusted Kaplan-Meier survival curves of first-year patient survival after LT in the past 14.5 years among liver transplant recipients stratified by age cohort.

doi:10.1371/journal.pone.0152324.g002 


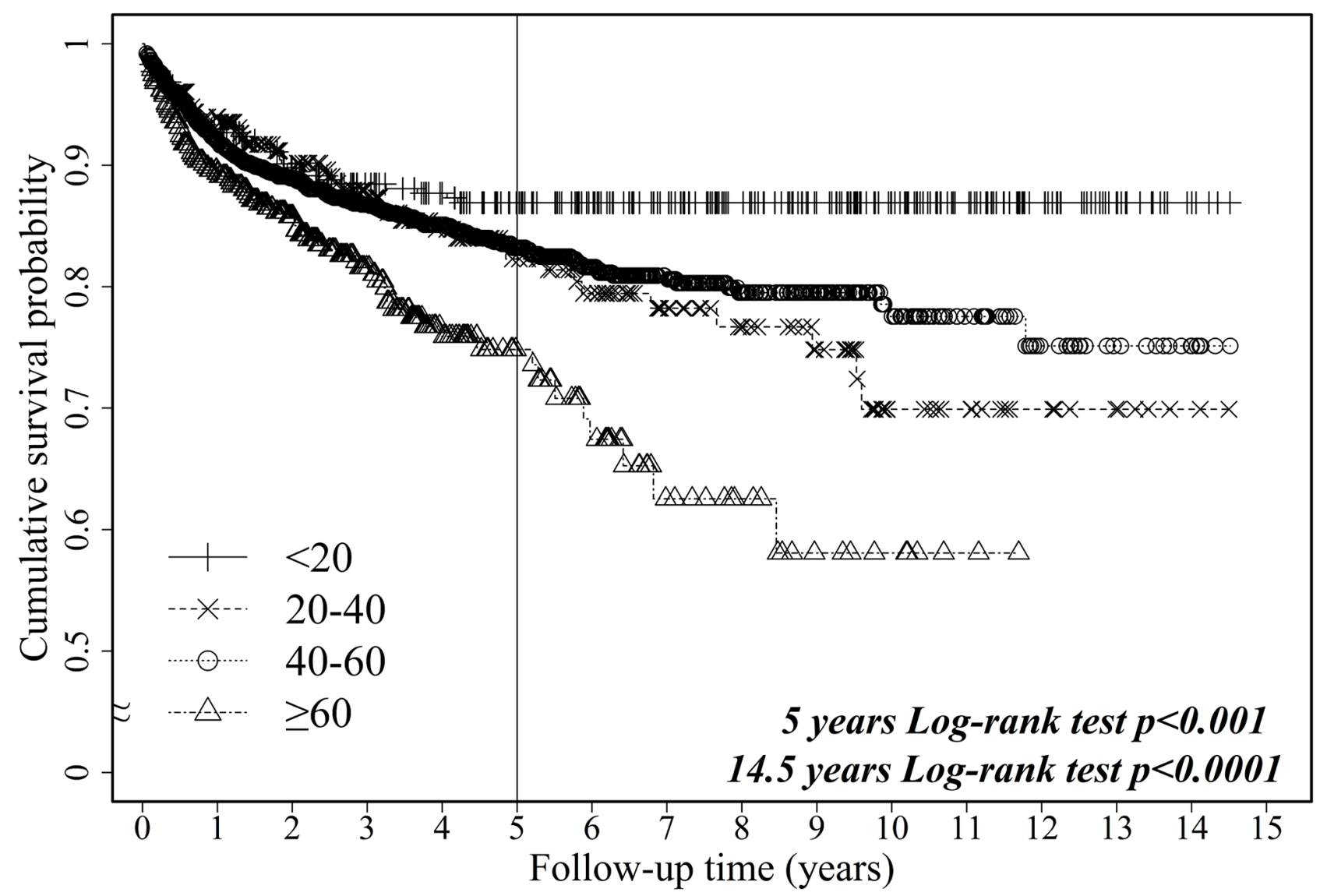

Fig 3. Unadjusted Kaplan-Meier survival curves of risk of mortality after liver transplantation in the past 14.5 years stratified by age cohort. doi:10.1371/journal.pone.0152324.g003

\section{Discussion}

Considering associated medical comorbidities and clinical outcomes is essential while formulating policies on organ transplant allocation. There are several concerns related to older LT recipients, including whether they have similar survival rates as their younger counterparts. To our knowledge, the present study is the first to examine data from a large database and determine whether elderly LT recipients have significantly higher overall mortality rates.

From the NHIRD, we found that an increasing number of elderly patients are undergoing LT surgery [1,7]. The results of the present study also showed that overall survival is low in elderly LT recipients. The mortality rates of recipients aged $\geq 60$ years in the transplant cohort were compared with those of individuals aged $\geq 60$ years from the general Taiwanese population during the same time period, and significantly higher mortality rates were observed in the transplant population. Thus, age was found to be a major risk factor for post-LT mortality, indicating that elderly LT recipients must be properly screened according to the presence or absence concomitant risk factors (including age and comorbidities) [8-12]. We recommend that future studies focus on elderly LT patients, which may supply clinicians with data for better risk stratification among elderly LT candidates.

Renal insufficiency is an important indicator of post-LT mortality and morbidity. Irrespective of age, patients undergoing dialysis in the present study showed a higher LT mortality rate. Renal replacement therapy before LT has been found to have a strong correlation with poor short- and long-term patient survival among LT patients [13-15]. Further, renal dysfunction 


$$
\begin{aligned}
+ \text { Dialysis } & =28.95 \% \\
+\mathrm{CAD} & =19.91 \% \\
+\mathrm{CKD} / \mathrm{ESRD} & =16.52 \% \\
+\mathrm{HCC} & =16.21 \% \\
+\mathrm{CHF} & =16.16 \% \\
+\mathrm{DM} & =15.62 \% \\
+ \text { Peptic ulcer } & =13.56 \% \\
+ \text { Male } & =13.17 \%
\end{aligned}
$$

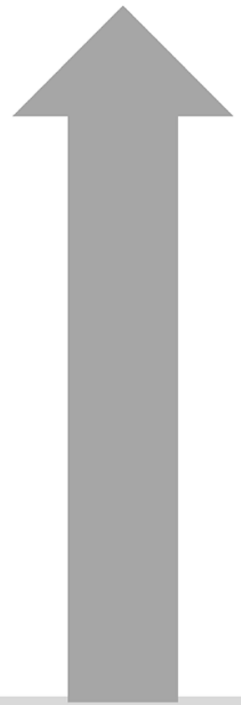

$$
\begin{aligned}
& + \text { Dialysis }=33.33 \% \\
& +\mathrm{CHF}=25.34 \% \\
& +\mathrm{CKD} / \mathrm{ESRD}=24.11 \% \\
& + \text { Female }=20.40 \% \\
& + \text { Peptic ulcer }=19.42 \% \\
& +\mathrm{HCC}=19.10 \% \\
& +\mathrm{DM}=19.07 \%
\end{aligned}
$$

$$
\begin{aligned}
\text { Age }<60 & =12.77 \% \\
& + \text { Female }=11.72 \%
\end{aligned}
$$

Mortality rate with age

$$
\text { Age } \geq 60=17.92 \%
$$

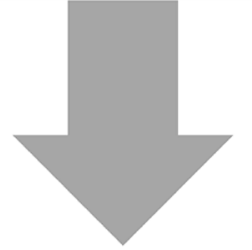

$$
\begin{aligned}
& + \text { Male }=16.10 \% \\
& +\mathrm{CAD}=12.61 \%
\end{aligned}
$$

Fig 4. Risk of death among liver transplant recipients aged $<60$ or $\geq 60$ years during a median follow-up period of 2.85 years posttransplantation

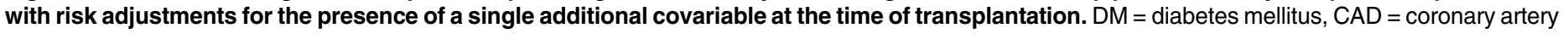
disease, $\mathrm{CHF}=$ congestive heart failure, $\mathrm{CKD} / \mathrm{ESRD}=$ chronic kidney disease/end-stage renal disease, $\mathrm{HCC}=$ hepatocellular carcinoma.

doi:10.1371/journal.pone.0152324.g004

Table 2. Multivariable Cox proportional hazard model for age-related mortality after transplantation.

\begin{tabular}{llll}
\hline Variable & Hazard Ratio & $\mathbf{9 5 \%} \mathbf{C l}$ & $\boldsymbol{p}$-value \\
\hline Age $\geq 60$ v.s. $<60^{*}$ & 1.475 & $1.154-1.887$ & 0.0020 \\
\hline Dialysis & 2.083 & $0.985-4.405$ & 0.0547 \\
\hline $\mathrm{DM}$ & 1.107 & $0.876-1.399$ & 0.3929 \\
\hline $\mathrm{CAD}$ & 1.177 & $0.816-1.698$ & 0.4424 \\
$\mathrm{CHF}$ & 1.218 & $0.626-2.368$ & 0.5617 \\
\hline $\mathrm{CKD}$ & 1.210 & $0.744-1.969$ & 0.4424 \\
$\mathrm{PU}$ & 1.118 & $0.918-1.361$ & 0.3929 \\
\hline $\mathrm{HCC}$ & 1.400 & $1.149-1.705$ & 0.0009 \\
& The model was stratified by the risk groups (the number of comorbidities) & \\
\hline Age-related (comorbidities) & Hazard Ratio & $95 \%$ Cl & $\boldsymbol{p}$-value \\
Age $\geq 60$ v.s. $<60$ (none) & 2.374 & $1.320-4.270$ & 0.0039 \\
\hline Age $\geq 60$ v.s. $<60$ (one) & 1.327 & $0.852-2.066$ & 0.2104 \\
Age $\geq 60$ v.s. $<60$ (over one) & 1.425 & $1.033-1.967$ & 0.0310 \\
\hline
\end{tabular}

$\mathrm{Cl}=$ confidence interval; $\mathrm{DM}=$ diabetes mellitus, $\mathrm{CAD}=$ coronary artery disease, $\mathrm{CHF}=$ congestive heart failure, $\mathrm{CKD}=$ chronic kidney disease, $\mathrm{PU}=$ peptic ulcer, $\mathrm{HCC}=$ hepatocellular carcinoma. * Model adjusted for risk factors including dialysis, DM, CAD, CHF, CKD, PU and HCC. 
before LT surgery has been reported to make transplant recipients susceptible to bacterial or fungal infections [16,17], posttransplant sepsis, prolonged intensive care unit stay [18], requiring renal replacement therapy [19], and greater overall cost of treatment [20,21].

In our study, after adjusting major risk factors, the impact of the age remained significant. Besides that, older LT patient with more medical comorbidities, the impact of the age is also significant. Therefore, what we need to do is optimizing the selection of elderly patients, this might minimize the difference. With the same indications of younger LT patients, we should evaluate elderly patients with good functional status without significant medical comorbidities for transplantation [22]. If, the elderly become too ill, the best way is to advise from transplant. Because death followed prolonged post-LT hospital course is more shattering than death itself, especially if this could be predicted before LT.

The present large retrospective population-based cohort study does have some limitations. Although the National Health Insurance Bureau regularly cross-checks each hospital's claims in order to reduce coding infractions and diagnoses and coding in hospitals and NHIRD services are generally considered accurate, the data are still susceptible to human errors, for example, inaccurate coding [23]. In addition, the NHIRD is a secondary database and lacks actual test data, including the physical examination and laboratory findings of patients, specific etiological data for end-stage liver disease leading to LT, and models for end-stage liver disease scores, which are related to patient mortality [24-26]. The NHIRD database is lack of the cause of death and allograft loss. Since cause of death and allograft loss were not analyzed, it remains to be the limitation of the study. Finally, although this population-based cohort study shows the relationship between age, comorbidities, and mortality among LT recipients, precise causality remains unknown $[5,6,27,28]$.

\section{Conclusion}

Liver transplant recipients aged $\geq 60$ years show higher mortality rates compared to similarly aged individuals from the general population as well as LT recipients aged $<60$ years. This increased mortality seems to be associated with medical comorbidities, especially in dialysis patients. We believe that our findings should not be a factor preventing elderly candidates from receiving transplants; rather, they should enable clinicians to perform better risk stratification for elderly transplant candidates. We also recommend that further prospective studies be conducted to understand how age and comorbidities affect mortality in elderly LT recipients.

\section{Supporting Information}

S1 Fig. Number of recepients after liver transplantation. (XLSX)

\section{S2 Fig. First year mortality of transplant patients.}

(XLSX)

\section{Acknowledgments}

This study was based in part on data from the NHIRD provided by the Bureau of National Health Insurance, Department of Health, and managed by the National Health Research Institutes. The interpretation and conclusions contained herein do not represent the views of the Bureau of National Health Insurance, Department of Health or National Health Research Institutes. 


\section{Author Contributions}

Conceived and designed the experiments: H-PC H-PY. Performed the experiments: H-PC YFT. Analyzed the data: H-PC F-CL J-RL. Contributed reagents/materials/analysis tools: F-CL H-PY. Wrote the paper: H-PC Y-FT H-PY J-RL.

\section{References}

1. Wilson GC, Quillin RC 3rd, Wima K, Sutton JM, Hoehn RS, Hanseman DJ, et al. Is liver transplantation safe and effective in elderly ( $\geqq 70$ years) recipients? A case-controlled analysis. HPB (Oxford). 2014; 16: 1088-1094.

2. Aduen JF, Sujay B, Dickson RC, Heckman MG, Hewitt WR, Stapelfeldt WH, et al. Outcomes after liver transplant in patients aged 70 years or older compared with those younger than 60 years. Mayo Clin Proc. 2009; 84: 973-978. doi: 10.1016/S0025-6196(11)60667-8 PMID: 19880687

3. Pungpapong S, Kim WR, Poterucha JJ. Natural history of hepatitis B virus infection: an update for clinicians. Mayo Clin Proc. 2007; 82: 967-975. PMID: 17673066

4. Ni YH, Huang LM, Chang MH, Yen CJ, Lu CY, You SL, et al. Two decades of universal hepatitis B vaccination in Taiwan: impact and implication for future strategies. Gastroenterology. 2007; 132: 12871293. PMID: 17433322

5. Haagsma EB, Hagens VE, Schaapveld M, van den Berg AP, de Vries EG, Klompmaker IJ, et al. Increased cancer risk after liver transplantation: a population-based study. J Hepatol. 2001; 34: 84-91. PMID: 11211912

6. Aberg F, Pukkala E, Hockerstedt K, Sankila R, Isoniemi H. Risk of malignant neoplasms after liver transplantation: a population-based study. Liver Transpl. 2008; 14: 1428-1436. doi: 10.1002/lt.21475 PMID: 18825704

7. Grat M, Kornasiewicz O, Grat K, Antczak A, Ligocka J, Holowko W, et al. Short and long-term outcomes after primary liver transplantation in elderly patients. Pol Prz Chir. 2013; 85: 581-588.

8. Bjoro K, Hockerstedt K, Ericzon BG, Friman S, Hjortrup A, Keiding S, et al. Liver transplantation in patients over 60 years of age. Transpl Int. 2000; 13 Suppl 1: S165-S170. PMID: 11111989

9. Pirsch JD, Kalayoglu M, D'Alessandro AM, Voss BJ, Armbrust MJ, Reed A, et al. Orthotopic liver transplantation in patients 60 years of age and older. Transplantation. 1991; 51: 431-433. PMID: 1994539

10. Karatzas T, Olson L, Ciancio G, Burke GW 3rd, Spires G, Cravero L, et al. Expanded liver donor age over 60 years for hepatic transplantation. Transplant Proc. 1997; 29: 2830-2831. PMID: 9365579

11. Norrby J, Liden H, Gabel M, Friman S, Olausson M. Early outcome of liver transplantation using donors over 60 years of age. Transplant Proc. 2001; 33: 2516-2517. PMID: 11406232

12. Serrano MT, Garcia-Gil A, Arenas J, Ber Y, Cortes L, Valiente $C$, et al. Outcome of liver transplantation using donors older than 60 years of age. Clin Transplant. 2010; 24: 543-549. doi: 10.1111/j.1399-0012 2009.01135.x PMID: 19925474

13. Bilbao I, Charco R, Balsells J, Lazaro JL, Hidalgo E, Llopart L, et al. Risk factors for acute renal failure requiring dialysis after liver transplantation. Clin Transplant. 1998; 12: 123-129. PMID: 9575400

14. Contreras G, Garces G, Quartin AA, Cely C, LaGatta MA, Barreto GA, et al. An epidemiologic study of early renal replacement therapy after orthotopic liver transplantation. J Am Soc Nephrol. 2002; 13 228-233. PMID: 11752042

15. Fraley DS, Burr R, Bernardini J, Angus D, Kramer DJ, Johnson JP. Impact of acute renal failure on mortality in end-stage liver disease with or without transplantation. Kidney Int. 1998; 54: 518-524. PMID: 9690218

16. De Meyer M, Wyns W, Dion R, Khoury G, Pirson Y, van Ypersele De Strihou C. Myocardial revascularization in patients on renal replacement therapy. Clin Nephrol. 1991; 36: 147-151. PMID: 1934671

17. Campbell MS, Kotlyar DS, Brensinger CM, Lewis JD, Shetty K, Bloom RD, et al. Renal function after orthotopic liver transplantation is predicted by duration of pretransplantation creatinine elevation. Liver Transpl. 2005; 11: 1048-1055. PMID: 16123966

18. Brown RS Jr, Lake JR, Ascher NL, Emond JC, Roberts JP. Predictors of the cost of liver transplantation. Liver Transpl Surg. 1998; 4: 170-176. PMID: 9516571

19. Gonwa TA, Klintmalm GB, Levy M, Jennings LS, Goldstein RM, Husberg BS. Impact of pretransplant renal function on survival after liver transplantation. Transplantation. 1995; 59: 361-365. PMID: 7871566

20. Nair S, Verma S, Thuluvath PJ. Pretransplant renal function predicts survival in patients undergoing orthotopic liver transplantation. Hepatology. 2002; 35: 1179-1185. PMID: 11981768 
21. Brown RS Jr, Lombardero M, Lake JR. Outcome of patients with renal insufficiency undergoing liver or liver-kidney transplantation. Transplantation. 1996; 62: 1788-1793. PMID: 8990364

22. Keswani RN, Ahmed A, Keeffe EB. Older age and liver transplantation: a review. Liver Transplantation. 2004; 10: 957-967. PMID: 15390320

23. Lin $\mathrm{HC}$, Xirasagar S, Chen $\mathrm{CH}, \mathrm{Hwang} \mathrm{YT}$. Physician's case volume of intensive care unit pneumonia admissions and in-hospital mortality. Am J Respir Crit Care Med. 2008; 177: 989-994. doi: 10.1164/ rccm.200706-8130C PMID: 18263804

24. Ferraz-Neto BH, Zurstrassen MP, Hidalgo R, Meira-Filho SP, Rezende MB, Paes AT, et al. Analysis of liver transplantation outcome in patients with MELD Score > or $=30$. Transplant Proc. 2008; 40: 797799. doi: 10.1016/j.transproceed.2008.03.016 PMID: 18455020

25. Akyildiz M, Karasu Z, Arikan C, Kilic M, Zeytunlu M, Gunsar F, et al. Impact of pretransplant MELD score on posttransplant outcome in living donor liver transplantation. Transplant Proc. 2004; 36: 1442 1444. PMID: 15251354

26. Onaca NN, Levy MF, Netto GJ, Thomas MJ, Sanchez EQ, Chinnakotla S, et al. Pretransplant MELD score as a predictor of outcome after liver transplantation for chronic hepatitis C. Am J Transplant. 2003; 3: 626-630. PMID: 12752320

27. Liu PY, Cheng SB, Lin CC, Lin CH, Chang SN, Cheng CY, et al. Cytomegalovirus disease after liver transplantation: a nationwide population-based study. Transplant Proc. 2014; 46: 832-834. doi: 10. 1016/j.transproceed.2013.12.009 PMID: 24767359

28. Kaneko J, Sugawara Y, Tamura S, Aoki T, Sakamoto, Hasegawa K, et al. De novo malignancies after adult-to-adult living-donor liver transplantation with a malignancy surveillance program: comparison with a Japanese population-based study. Transplantation. 2013; 95: 1142-1147. PMID: 23572128 